\title{
A RESISTÊNCIA ESTADUAL ÀS POLÍTICAS DE DONALD TRUMP: O CASO DA CALIFÓRNIA
}

\author{
Débora Figueiredo Mendonça do Prado \\ Isabella Ferrarez Fernandes Lopes²
}

\begin{abstract}
O objetivo deste artigo é analisar as tensões entre estados e governo federal nas temáticas imigratórias e ambientais, com foco na atuação do estado da Califórnia. Buscaremos argumentar que a relação entre os estados e o governo nacional no atual governo Trump possui um caráter conflituoso, aproximando-se do federalismo dual, o que contraria a literatura corrente, que considera tal modelo superado. Partimos da hipótese de que esse tipo de atuação coloca em xeque a percepção de que a condução da política exterior dos Estados Unidos é unificada e restrita ao governo central. Argumentaremos também que a reação dos estados ao governo Trump está vinculada a motivações partidárias, sobretudo em estados com um perfil mais progressista. Para isso, analisaremos a atuação do estado da Califórnia, tendo em vista sua liderança na articulação desse movimento.
\end{abstract}

Palavras-chave: federalismo; estados; relações internacionais; Trump; Califórnia.

\section{STATE GOVERNMENTS RESISTANCE TO DONALD TRUMP ADMINISTRATION: THE CALIFORNIAN CASE}

This article analyzes the tensions between federal states and the U.S. White House in the immigration and environmental themes, with a focus on the state of California. We argue that the relationship between federal states and the national government in the current Trump government has a more conflictive character. It can be understood as a new kind of dual federalism, which is contrary to the current literature that considers such a model to be overcome. We start from the hypothesis that this type of action questions the perception that the conduct of US foreign policy is unified and restricted to the central government. We argue that the reaction of states to Trump's government is linked to partisan motivations, especially in states with a more progressive profile. To do so, we will analyze the actions of the state of California as well as it's leadership in the articulation of this movement.

Keywords: federalism; states; international relations; Trump; California.

\section{RESISTENCIA ESTATAL A LAS POLÍTICAS DE DONALD TRUMP: EL CASO DE CALIFORNIA}

El propósito de este documento es analizar las tensiones entre los estados y el gobierno federal en temas de inmigración y medioambientales, enfocándose en el desempeño del estado de California. Argumentaremos que la relación entre los estados y el gobierno nacional en el actual gobierno de Trump tiene un carácter conflictivo, que se aproxima al federalismo dual, lo que es contrario

1. Pesquisadora do Instituto Nacional de Ciência e Tecnologia para Estudos sobre os Estados Unidos (INCT-INEU); e professora adjunta no curso de relações internacionais da Universidade Federal de Uberlândia (UFU).

E-mail:<debfbp@gmail.com>.

2. Analista em relações internacionais. E-mail: <isa_ferrarez@hotmail.com>. 
a la literatura actual, que considera que dicho modelo está desactualizado. Asumimos que este tipo de acción desafía la percepción de que la conducta de la política exterior de Estados Unidos está unificada y restringida al gobierno central. También argumentaremos que la reacción de los estados al gobierno de Trump está vinculada a motivaciones partidistas, especialmente en estados con un perfil más progresivo. Para esto, analizaremos el desempeño del estado de California, en vista de su liderazgo en la articulación de este movimiento.

Palabras clave: federalismo; estados; relaciones internacionales; Trump; California.

JEL: D7; D72.

\section{INTRODUÇÃO}

No senso comum norte-americano, existe a percepção de que a nação mantém uma postura unificada no campo da política doméstica e internacional, ainda que os estados gozem de relativa autonomia. Esse mito está presente nas análises relativas à história da fundação do país, da Revolução à Constituição de $1787,{ }^{3}$ que enaltecem o caráter coeso da nova república. Nesse entendimento, a aprovação da Constituição representou um marco na superação das divergências regionais, garantindo um cenário que pacificou os interesses daqueles que defendiam um governo central forte e também dos defensores da autonomia estadual.

A ratificação da nova Constituição, contudo, foi um processo difícil, marcado por fortes tensionamentos em decorrência de interpretaçóes distintas sobre qual formato o país deveria adotar. A substituição da Confederação de Estados, adotada logo após a independência do país, pela república instituída se deu com base em um consenso mínimo entre os estados que defendiam uma maior transferência de autoridade ao governo federal e aqueles que defendiam a manutenção da autonomia dos estados.

A importância desse processo não é somente histórica. As tensões identificadas entre os defensores da centralização junto ao governo federal e aqueles que defendiam a autonomia dos estados permanecem como elementos centrais para compreender a formação do país e as contradiçôes identificadas no período contemporâneo. Tais choques também ocorrem em importantes temas da política exterior, evidenciando um país mais próximo de uma nação fragmentada. São exemplos desse tensionamento a reação dos estados às políticas adotadas por Trump na temática imigratória e a busca pela liderança na temática ambiental.

O objetivo deste trabalho será analisar esse processo, com foco na atuação do estado da Califórnia no que tange às políticas imigratórias e ambientais. Dito isso, buscaremos argumentar que a relação entre os estados e o governo nacional no atual governo Trump possui um caráter mais conflituoso, aproximando-se

3. 0 debate sobre os mitos envolvendo a fundação dos Estados Unidos pode ser identificado em Raphael (2014), Wills (2018), Hobsbawm (2007), Zinn (2010) e Fox (2003). 
do federalismo dual, o que contraria a literatura corrente, que considera tal modelo superado. Partimos da hipótese de que esse tipo de atuação coloca em xeque a percepção de que a condução da política exterior dos Estados Unidos é unificada e restrita ao governo central. Assim, primeiramente, buscaremos analisar a formação do federalismo norte-americano, caracterizando esse modelo e as tensốes entre estados e governo central. Em seguida, focaremos a reação dos estados norte-americanos às medidas adotadas pelo governo Donald Trump, destacando a atuação do estado da Califórnia. Com isso, será possível identificar de que modo os estados vêm assumindo um papel importante na resistência às políticas imigratórias implementadas pelo governo central, bem como no posto de liderança assumido por esses atores na manutençáo e nos compromissos assumidos internacionalmente vinculados às políticas de mudanças climáticas.

\section{A INAUGURAÇÃO DO FEDERALISMO NORTE-AMERICANO E AS TENSÕES ENTRE ESTADOS E GOVERNO CENTRAL}

A falsa percepção de unidade e harmonia de interesses dos estados no processo de fundação dos Estados Unidos está presente desde as análises sobre a Revolução Norte-Americana, passando pela Declaração de Independência até os debates da Convençấo Constitucional. Esta última, inclusive, formulou a proposta da nova Constituição do país em 1787, que reforça o papel dos federalistas na construção de uma nação centralizada. Como argumenta Zinn (2010, p. 93, tradução nossa), "a mitologia em torno dos Pais Fundadores persiste".

As interaçóes entre os estados e o governo federal, entretanto, são marcadas tanto pela cooperação quanto pelo conflito. Esse padrão de relacionamento possui características vinculadas aos modelos do federalismo dual e do cooperativo, e tem suas origens na fundação da república norte-americana desde o período da Confederação de Estados até a formação do federalismo moderno (Anderson, 2009).

O primeiro modelo adotado após a independência, o da Confederação de Estados, instituiu um formato altamente limitador ao governo nacional, e a motivação para isso está vinculada à desconfiança dos estados em formar um governo nacional forte. Os artigos reconheciam a necessidade de unificação entre os treze estados, mas mantinham sua independência ao determinar que o governo federal não poderia interferir nos assuntos individuais de cada estado. O Congresso era o principal órgão do governo nacional e tinha como responsabilidade a garantia da segurança externa dos estados e o exercício do poder exclusivo de determinar a guerra ou a paz, bem como o estabelecimento de tratados e alianças. Apesar disso, o órgão possuía limitações significativas, pois, como determinava o décimo artigo da Confederação, suas decisões precisariam contar com uma ampla maioria para a aprovação. 
A estrutura frágil desse sistema já era conhecida, mas a dificuldade em construir a unidade entre os estados naquele período foi maior. À medida que a nação se desenvolvia e fortalecia seus intercâmbios comerciais no exterior, ficou mais evidente a necessidade de reformular o sistema. Foi entáo que, em 1787, após os debates realizados na Convenção Constitucional da Filadélfia, os estados firmaram o Grande Compromisso, ou Compromisso de Connecticut, ${ }^{4}$ com a finalização de uma nova proposta constitucional e superação do modelo de Confederação de Estados. A proposta buscou solucionar as tensóes ${ }^{5}$ entre os large e small states ao prever o estabelecimento de um sistema dual de representação no Congresso: na Casa dos Representantes, cada estado teria o número de assentos proporcional à sua população. Além disso, previa a formação de um Executivo único, sob o comando do presidente. Esse processo foi um marco na formação dos Estados Unidos, ao inaugurar o federalismo moderno norte-americano com o abandono do sistema de confederação e a ratificação da nova proposta constitucional (Anderson, 2009).

É importante destacar, entretanto, que a aprovação da proposta foi difícil, e o texto constitucional foi aprovado com a diferença de apenas um voto. A dificuldade para a aprovação do plano refletiu a insatisfação dos estados, sobretudo daqueles contrários ao fortalecimento do governo nacional. Esse período também marcou um momento importante de reflexão sobre o federalismo a ser adotado, fundamentado em debates realizados entre os federalistas e os antifederalistas, ${ }^{6} \mathrm{em}$ paralelo às negociaçôes da Convenção da Filadélfia, que se estenderam até 1788. A importância desses textos não é apenas histórica: Cornell (1999) destaca que o debate realizado naquele período entre os defensores da autonomia estadual e os da centralização de poderes se mantém vivo na história atual do país, exercendo um papel determinante na vida política norte-americana contemporânea. Como ressalta o autor, os princípios e ideias dos antifederalistas continuam a definir o espírito da política norte-americana, sendo utilizados como referência para a interpretação dos artigos da Constituição nas decisôes da Suprema Corte em casos de conflitos entre os estados e o governo central.

4. Referindo-se aos principais delegados da proposta, Roger Sherman e Oliver Ellsworth.

5. 0 tema mais problemático envolvia a questão da representação. Os delegados dos estados maiores entendiam que, como sua contribuição financeira ao governo nacional e aos recursos de defesa seria maior, eles deveriam obter um número maior de assentos no Senado. Em contrapartida, os estados menores entendiam que todos os estados deveriam contar com representação igualitária nas duas casas do Legislativo. 0 objetivo da proposta foi então conciliar os interesses dos dois grupos.

6. As discussões sobre a ratificação da Constituição Federal tiveram grande repercussão com a publicação e divulgação dos argumentos contrários à nova proposta em jornais, artigos e panfletos em todo o país. As cartas foram elaboradas por vários autores, publicadas em sua maioria anonimamente, com o receio de que a divulgação de seus nomes poderia prejudicá-los. Enquanto os textos antifederalistas buscavam apresentar as falhas da nova proposta constitucional, destacando a forma e as características do que deveria ser um governo livre e os excessos de poder destinados ao Executivo e Judiciário, os autores federalistas defendiam a necessidade de estabelecer um governo federal centralizado, que mantivesse a união dos estados, apresentando as deficiências dos artigos da Confederação (Storing e Dry, 1985). 
De acordo com Zimmerman (1996), o federalismo adotado nesse período está centrado em dois modelos: o dual e o cooperativo. ${ }^{7}$ Segundo o autor, o primeiro arranjo adotado pelo país foi o federalismo dual, ${ }^{8}$ no qual o governo federal e os estados mantinham sua autonomia, sendo considerados esferas de poder com igual importância. Corwin (1950) define o federalismo dual como um sistema em que o governo nacional é apenas um dos poderes enumerados, tendo suas atribuiçôes limitadas. Nesse modelo, as duas esferas de governo são soberanas e iguais, e o relacionamento entre os dois centros de poder é marcado mais pela tensão do que pela colaboração. ${ }^{9} \mathrm{O}$ federalismo cooperativo, por sua vez, pode ser definido como um modelo no qual

os estados preservaram sua integridade não através de uma nítida separação de seus sistemas políticos do sistema nacional, mas dentro de uma estrutura intrincada de relaçôes cooperativas que preservam sua integridade estrutural, enquanto experimentam uma atuação conjunta funcional de todos os níveis de governo funcionalmente na tarefa comum de servir o povo americano (Elazar, 1966 apud Sager, 1998, p. 34, traduçáo nossa). ${ }^{10}$

Argumenta-se que o arranjo cooperativo foi estabelecido pondo fim ao modelo de competição por poder entre estados e governo federal. Parte da literatura especializada no tema afirma que o modelo dual foi marcante durante o período constitucional (1790) e encerrado no governo Franklin Roosevelt (1930), em consequência das políticas envolvendo o New Deal, e levou o governo federal a trabalhar de forma mais cooperativa com os estados. Outra corrente destaca que a adoção do arranjo cooperativo foi anterior aos anos 1930. Para Elazar (1987) e Sager (1998), o fim da competição por poder entre estados e governo federal foi anterior ao New Deal - Elazar (1987), inclusive, argumenta que a cooperação significativa entre estados e governo federal esteve presente desde o início do século XIX, durante a Guerra Civil.

7. Há autores que subdividem os arranjos federativos nos Estados Unidos em outros modelos. Além do federalismo dual (ou "layer-cake" federalism) e do federalismo cooperativo (ou "marble-cake" federalism), há uma literatura que trabalha com a inclusão do conceito de federalismo coercitivo (coercive federalism). Este último refere-se a situaçõ̃es nas quais o governo federal interfere em assuntos antes exclusivos dos governos estaduais. Kincaid (1990) destaca que esse processo é identificado nos últimos sessenta anos. Para um aprofundamento desse modelo de federalismo, ver Wright (1988), Walker, (1989), Edwards e Lippucci (1998), Anderson (2009) e Morgan e Davies (2008).

8. Expressão cunhada por Corwin (1950), também conhecida pelo termo federalismo layer cake. Ela foi criada por Grodzins (1966), descrevendo um sistema no qual instituições e funções em cada nível de governo são consideradas separadamente.

9. "1. 0 governo nacional é apenas um dos poderes enumerados; 2. Além disso, os objetivos que ele pode promover constitucionalmente são poucos; 3. Dentro de suas respectivas esferas, os dois centros de governo são 'soberanos' e, portanto, 'iguais'; 4. A relação dos dois centros entre si é mais de tensão do que de colaboração" (Corwin, 1950, p. 4, tradução nossa).

10. "The states have preserved their integrity not through a sharp separation of their political systems form the national system but within an intricate framework of cooperative relationships that preserve their structural integrity while trying all levels of government together functionally in the common task of serving the American people." 
Questionando a interpretação de que o federalismo dual está plenamente superado, argumentaremos neste trabalho que o federalismo norte-americano ainda mantém uma dinâmica ora dual, ora cooperativa. Ou seja, em determinados momentos, há tensóes no pacto federativo norte-americano mais próximas ao modelo dual.

Como podemos verificar, os conflitos envolvendo a autonomia dos estados e a atuação do governo nacional são parte da história dos Estados Unidos e do desenho institucional adotado no país. Vale destacar que as tensões envolvendo a atuação dos estados e as posições do governo central também estão presentes quando analisamos o relacionamento entre esses atores na arena internacional. Como destaca Sager (1998, p. 301, tradução nossa), na arena internacional, "a cooperação existe lado a lado com o 'federalismo conflituoso' em questóes como sançôes comerciais e preempção potencial de leis estaduais”.

Esse tipo de atuação estadual não é recente: os constrangimentos são identificados pela literatura ainda no século XIX, período em que foram registradas açóes vinculadas à promoção de políticas imigratórias (Frank, 1998), bem como ao estabelecimento de legislações estaduais destinadas à regulaçáo da imigração (Kline, 1983).

Nesse último caso, cabe destacar a controvérsia gerada entre os estados sulistas e a Grã-Bretanha em 1823, em decorrência das legislaçóes estaduais destinadas à regulação do tráfico de escravos e da imigração. Ao analisá-la, Kline (1983) destaca que a controvérsia se manteve sem que o governo federal conseguisse solucionar o caso nem mesmo por corte federal, fazendo com que a Grã-Bretanha estabelecesse consulados nos estados sulistas para negociar diretamente com eles a situação de seus marinheiros.

Conflitos e tensóes entre os estados e o governo central também podem ser identificados nos boicotes estaduais, prevendo restriçóes ao investimento e à atividade comercial a outros países, tais como a África do Sul no período do apartheid (Fry, 1998) e as sanções contra o governo de Burma/Myanmar, sob alegação de violação aos direitos humanos. Os dois casos geraram conflitos junto ao governo central, tendo o último sido encaminhado à Suprema Corte e à Organização Mundial do Comércio (OMC) (Prado, 2013).

No atual governo Trump, marcado pela forte polarização política, temos identificado um movimento crescente de ativismo estadual em reação às políticas utilizadas pelo governo central, pois elas estâo vinculadas a duas posiçóes polêmicas adotadas pelo governo e que acertaram em cheio os interesses dos estados: a aplicação de medidas restritivas à imigração e o abandono dos compromissos assumidos no âmbito das mudanças climáticas. 
A posição do governo central nesses dois temas teve forte reação no nível subnacional, com destaque para a atuação das cidades-santuário, ${ }^{11}$ que questionaram judicialmente as medidas adotadas por Trump na temática imigratória e reafirmaram compromissos assumidos no plano multilateral para as mudanças climáticas, na contramão do governo central.

$\mathrm{Na}$ próxima seção, analisaremos as ações adotadas pelos governos subnacionais, com foco na atuação do estado da Califórnia, sexta maior economia do país. Ele tem assumido a liderança nas ações de resistência às políticas adotadas por Trump, inclusive buscando ocupar um espaço de liderança na temática ambiental.

\section{A RESISTÊNCIA ESTADUAL ÀS AÇÕES DO GOVERNO CENTRAL PELO ESTADO DA CALIFÓRNIA}

O aumento no número de deportações de imigrantes em situação irregular foi uma promessa de campanha de Donald Trump. Logo após assumir a Casa Branca, o presidente implementou uma série de medidas destinadas à restrição da imigração no país, decorrentes da liberação de novas diretrizes, que objetivavam: i) ampliar o número de deportaçóes; e ii) acelerar os processos e ampliar os poderes da ICE) do Departamento de Segurança Interna dos Estados Unidos, vinculando o tema a uma questão de segurança nacional.

Entre as ações adotadas, podemos citar as ordens executivas nos 13.768 (Enhancing Public Safety in the Interior of the United States) e 13.767 (Border Security and Immigration Enforcement Improvements). A primeira ampliou as possibilidades de deportação para além dos casos já previstos no governo Obama, que permitia a deportaçáo de imigrantes condenados por crimes graves ou que representassem uma ameaça à segurança nacional. A segunda, por sua vez, abordou a questão do muro nas fronteiras, ao prever a ampliação da quantidade de agentes nas fronteiras com o objetivo de assegurar "a segurança e a integridade territorial dos Estados Unidos, bem como garantir que as leis de imigração da nação sejam executadas fielmente" (United States of America, 2017a, traduçáo nossa).

Ainda nesse período, o governo adotou a Ordem Executiva no 13.769 , intitulada Protecting the Nation from Foreign Terrorist Entry into the United States, que estabelecia restriçóes à entrada nos Estados Unidos de imigrantes e não imigrantes de países com maioria muçulmana (Síria, Irã, Sudão, Líbia,

11. De acordo com o memorando Enhancing Public Safety in the Interior of the United States de 2017, apresentado pelo procurador-geral Jeff Sessions em maio de 2017, as cidades-santuário são aquelas que se recusam a compartilhar certas informações relacionadas ao status de imigração com funcionários federais. Segundo o documento, serão consideradas inelegíveis as jurisdições que se recusarem a cumprir a ordem executiva, proibindo os governos locais de promulgar políticas que restrinjam ou proíbam as comunicações da polícia local com a Agência de Imigração e Alfândega (U.S. Immigration and Customs Enforcement - ICE). 
Somália, Iêmen e Iraque). O decreto gerou forte reação, causando protestos, e foi suspenso por tribunais federais. ${ }^{12}$ Um novo foi implementado, a Ordem Executiva no 13.780, chamada Protecting the Nation from Foreign Terrorist Entry into the United States Initial Section 11 Report, retirando o Iraque da lista ${ }^{13}$ e proibindo a emissão de vistos e entrada no país para cidadãos dos outros seis países mencionados no decreto anterior.

Outros compromissos e medidas voltados ao controle da imigração foram mantidos nos períodos subsequentes, com destaque para a decisão, em setembro de 2017, de pôr fim ao programa Deferred Action for Childhood Arrivals (DACA), aprovado por ordem executiva em 2012 durante o governo Obama, que prevê proteger adolescentes e jovens da deportação imediata. A situação de 1,8 milhão de jovens beneficiários do programa segue incerta, uma vez que a proposta bipartidária apresentada em fevereiro de 2018, buscando solucionar o caso, sofreu uma derrota no Senado (Teixeira, 2018). Apesar das incertezas, a decisão mais recente da Suprema Corte de não intervir no caso ao entender que a tramitação deve seguir nas cortes inferiores, em janeiro de 2019, representou uma derrota ao presidente. Por enquanto, os serviços de imigração devem continuar a aceitar os pedidos de renovação da autorização de imigraçáo dos jovens.

Em 2018, a questáo imigratória permaneceu como prioridade na agenda do governo, que recebeu intensas críticas ao implementar a política de tolerância zero, separando milhares de crianças de suas famílias ${ }^{14}$ em abrigos superlotados $;^{15}$ ao enviar 5.800 soldados para a fronteira do México como forma de conter a caravana de migrantes centro-americanos; e ao assinar uma ordem executiva que impedia a concessão de refúgio e suspendia por noventa dias a entrada de imigrantes pela fronteira com o México (Riotta, 2018). Uma derrota enfrentada pelo governo nessa temática, em fevereiro de 2019, foi a determinação da Justiça Federal de que o Departamento de Segurança Interna deve estender, até janeiro de 2020, a proteção aos mais de 250 mil imigrantes com possibilidade de deportação advindos de El Salvador, Haiti, Sudão e Nicarágua (Miroff, 2019).

$\mathrm{O}$ endurecimento anti-imigração do governo tem tido impacto direto na atuação das chamadas cidades-santuário, que negam a liberação de informaçóes sobre o status migratório de sua população. Além de declarar a ilegalidade de

12. A primeira decisão contrária à ordem foi da juíza Ann Donnelly, do Tribunal Federal Distrital no Brooklyn, que ordenou a permanência no país das pessoas retidas nos aeroportos. Ela se repetiu em outros estados, como Massachusetts, Virgínia, Washington, Minnesota, Óregon e Califórnia (Teixeira, 2017).

13. Segundo Teixeira (2018), essa mudança seria resultado da pressão dos secretários James Mattis (Defesa), Rex Tillerson (Estado) e John Kelly (Segurança Doméstica), em reconhecimento e pela manutenção da colaboração de iraquianos com americanos em Bagdá.

14. Apesar da afirmação oficial de que esta política foi encerrada, advogados de imigração no Texas denunciaram que o governo Trump continua separando crianças de suas famílias (Delgado, 2019).

15. Disponivel em: <https://bbc.in/2Xyc1jis. 
suas ações por violação das leis federais, o governo previu, na Ordem Executiva no 13.768 , a possibilidade de cortes orçamentários nos fundos federais caso esses atores subnacionais mantivessem a mesma conduta. Está previsto na seçâo 9 o seguinte.

Seção 9. Jurisdiçôes do Santuário. É política do poder executivo garantir, em toda a extensão da lei, que um Estado, ou uma subdivisão política de um Estado, cumpra com a 8 U.S.C. 1373.

(a) Para promover esta politica, o procurador-geral e o secretário, a seu critério e na medida consistente com a lei, garantirão que as jurisdiçôes que voluntariamente se recusem a cumprir a USC 1373 (jurisdiçóes do santuário) não são elegíveis para receber subsídios federais, exceto conforme necessário para fins de aplicaçáo da lei pelo procurador-geral ou pelo secretário. O secretário tem autoridade para designar, a seu critério e na medida consistente com a lei, uma jurisdição como jurisdição santuário. O procurador-geral tomará as medidas de execução apropriadas contra qualquer entidade que viole a 8 U.S.C. 1373, ou que possua estatuto, política ou prática que impeça ou dificulte a aplicação da lei federal (United States of America, 2017b, traduçáo nossa, grifo nosso).

Os tensionamentos entre estados e governo central também envolvem a temática ambiental. Trump questiona a veracidade das mudanças climáticas desde o período de sua campanha e tem demonstrado abertamente a rejeição a essa temática. $\mathrm{O}$ afastamento concreto dessa agenda ocorreu logo no início do governo, quando Trump anunciou sua intenção de retirada do Acordo de Paris ${ }^{16}$ e de reversão do Plano de Energia Limpa, além de outros esforços práticos para reduzir a poluição, afastando-se da promessa climática dos Estados Unidos para o mundo. ${ }^{17}$ Entre as justificativas apresentadas pelo governo para a saída do acordo estáo: i) a queda na geração do emprego e o impacto econômico negativo das medidas para os Estados Unidos; ii) os riscos de apagóes; e iii) o fato de que o país arcaria com o pagamento de bilhóes de dólares ao Green Climate Fund (Varinsky, Mosher e Schwartz, 2017).

Outra medida adotada pelo governo foi o esvaziamento da Agência de Proteção Ambiental (Environmental Protection Agency - EPA), por meio da implementação de medidas de desregulamentação do setor em benefício dos setores poluidores (Reis, 2017). Isso resultou na alteraçáo do funcionamento da agência, que passou a emitir memorandos unilaterais.

As políticas implementadas pelo governo Trump vêm enfrentando forte resistência no estado da Califórnia, que reagiu negativamente desde a vitória do

16. 0 Acordo de Paris foi assinado em 2016 e estabelece metas para limitar o aumento da temperatura global e reduzir a poluição emitida por fábricas e veículos, bem como frear o desmatamento, objetivando limitar o aumento da temperatura do planeta (UN, 2015).

17. Disponível em: <https://bit.ly/2AyeWfD>. 
candidato. O descontentamento da população motivou inclusive uma campanha pela separação do estado, denominada Yes California, que recebeu relativa visibilidade da mídia (Bernstein, 2017). Em 2018, outra tentativa nesse sentido foi implementada quando o então secretário de estado Alex Padilla anunciou uma proposta para uma consulta à população em 2020 sobre uma possível independência do estado (Manchester, 2018). A probabilidade de a separação acontecer é baixíssima, mas o movimento refletiu o descontentamento da população e a forte polarização no país com a vitória do republicano. Campanhas semelhantes a esta ocorreram no Texas, em rejeição à vitória de Obama (Salvador e Batista, 2017).

As açóes de liderança da Califórnia contra Trump são destaque na imprensa e têm sido identificadas como uma verdadeira guerra estadual ao governo (Purdum, 2019; Bruck, 2018). As medidas restritivas à imigração implementadas pelo presidente afetam diretamente interesses econômicos e políticos da região, uma vez que o estado da Califórnia possui o maior número de imigrantes no país. ${ }^{18}$ $\mathrm{O}$ abandono do multilateralismo na temática ambiental pelo governo central também afeta a agenda estadual, que tem como prioridade a implementação de políticas para as mudanças climáticas.

Para além dos benefícios ao meio ambiente, o estado da Califórnia utiliza-se do desenvolvimento de energias limpas como um catalisador econômico, uma vez que tal indústria emprega milhares de pessoas e atrai bilhóes de dólares em capital de risco de energia. Em 2015, cerca de 79 mil pessoas estariam empregadas nas indústrias de produção de energia solar e eólica no estado, ao passo que a Califórnia também lidera no montante de capital de risco de energia, visto que mais de US\$ 2 bilhóes teriam sido atraídos nesse mesmo ano. ${ }^{19}$ Em 2018, mais de um terço da energia produzida no estado da Califórnia seria proveniente de fontes solares, eólicas e geotérmicas, e cerca de $9 \%$ advêm de energia nuclear, ao passo que $49 \%$ utilizariam o gás natural, combustível fóssil considerado limpo (Ivanova, 2018).

Para além do estímulo à geração de energias renováveis, os impactos econômicos também são observados em nível de eficiência energética. Diversas legislaçóes foram promulgadas no estado para incentivar a eficiência energética e a

18. A Califórnia possui aproximadamente 10,5 milhões de imigrantes, sendo que residentes estrangeiros correspondem a 30\% da população das seis regiões. Ainda de acordo com o Instituto de Políticas Públicas da Califórnia, o estado possui mais de 2 milhões de imigrantes indocumentados. Mais informações disponiveis em: <http://www.ppic.org/ publication/immigrants-in-california/> e <https:/www.migrationpolicy.org/programs/data-hub/charts/us-immigrantpopulation-state-and-county>.

19. Disponível em: <https://bit.ly/2LUCDIt>. 
exploração de recursos alternativos, como a Senate Bill (SB) $1037^{20}$ e a Assembly Bill (AB) 2021, ${ }^{21}$ em 2005 e 2006. Entretanto, foi a AB 32, promulgada em 2006, que representou também no âmbito de eficiência energética um marco para o declínio do consumo de energia. ${ }^{22}$

O programa Cap-and-Trade do estado também tem por objetivo atingir as metas de redução de gases com a atração de investimentos. Ao estabelecer um custo para as emissôes de carbono por meio do programa, há um incentivo não só à redução das emissóes, mas também à produção de energias renováveis e eficiência energética na Califórnia, o que revela sua importante face econômica no estímulo à diminuição de emissóes de gases do efeito estufa.

Colocar-se como uma liderança norte-americana na promoção de políticas voltadas para as mudanças climáticas tem uma importante face econômica para a Califórnia. Como destaca Rabe (2008, p. 112, tradução nossa), "tornou-se cada vez mais claro que a Califórnia pretende com esse esforço maciço obter a estabilização de emissóes adicionais, minimizar custos internos e maximizar suas oportunidades de desenvolvimento econômico".

Nas eleiçôes de 2018, o antitrumpismo tomou conta da agenda política, e o resultado da eleição foi reflexo desse processo. $\mathrm{Na}$ Califórnia, os democratas conquistaram mais cinco assentos na Câmara (possuem agora 46 assentos, contra 7 dos republicanos) e elegeram para o Senado a democrata Dianne Feinstein. O democrata Gavin Newson, por sua vez, foi eleito governador com 61,9\% dos votos. ${ }^{23}$ Os principais eixos da resistência estadual ao governo Trump envolvem a atuação da Procuradoria-Geral do Estado contra as medidas da Casa Branca, a implementação de leis estaduais contrárias às políticas do governo nacional e o envolvimento direto do estado na implementação das medidas de mudanças climáticas na arena internacional.

No Judiciário, as batalhas contra a Casa Branca têm sido frequentes: o procurador-geral do estado, Xavier Becerra, processou o governo nacional 46 vezes nos últimos dois anos (Purdum, 2019). Entre as ações, tivemos o processo para a continuação do programa DACA e as medidas contrárias ao veto migratório

20. Este projeto de lei exigiria que a comissão, em consulta com a Comissão de Energia da Califórnia (CEC), identificasse todas as economias potencialmente alcançáveis em termos de economia de eficiência energética e estabelecesse metas de eficiência a serem atingidas por uma corporação elétrica de acordo com seu plano de aquisições. 0 projeto exigiria que o plano de compras de uma empresa elétrica incluísse uma demonstração de que a empresa elétrica responderá primeiro às necessidades não atendidas de recursos por meio de toda a eficiência energética disponível e de recursos de redução de demanda que sejam rentáveis, confiáveis e viáveis (California, 2005, tradução nossa).

21. Requer que todas as concessionárias de energia elétrica e gás natural cumpram as metas de eficiência energética estabelecidas pela CEC e pela Comissão de Utilidades Públicas da Califórnia (California Public Utilities Commission CPUC) (California, 2006, tradução nossa).

22. Disponível em: <https://bit.ly/2GDY7Fj>.

23. Disponivel em: <https://nyti.ms/2PNNhlW>. 
a muçulmanos. O processo mais recente, contra as tentativas para impedir a construção do muro na fronteira com o México, foi iniciado em fevereiro de 2019. Após Trump declarar emergência nacional para a liberação de recursos a fim de construir o muro, o governador da Califórnia declarou: "Our message to the White House is simple: CA will see you in court" (Purdum, 2019). E, ainda, completou: "Instead of fighting the actual threats facing Americans, the president has chosen to undermine our Constitution and fan the flames of nativism and xenophobia. This is not a 'national emergency". It's a national disgrace" (Purdum, 2019). No total, dezesseis estados entraram na justiça distrital da Califórnia contra a declaração de Trump (Alvarez, 2019).

Enfrentamentos desse tipo também ocorrem no nível local, com a reação das cidades às medidas impostas pelo governo Trump. São Francisco foi a primeira cidade a apresentar um recurso legal contra a ordem executiva do governo que visava combater a atuação das cidades-santuário em 2017 . O processo, apresentado pelo procurador Denis Herrera, questionou a medida ao alegar que o decreto federal viola a décima emenda da Constituição norte-americana.

O município de Santa Clara, na Califórnia, também enfrentou o Ministério da Justiça no Tribunal Federal em abril do mesmo ano. As duas cidades tentaram obter uma liminar preliminar contra a ordem executiva do presidente Trump, que procura privar de fundos federais as cidades-santuário e os estados, argumentando que a medida era inconstitucional. Nesse período, o juiz William Orrick, da Corte Distrital de São Francisco, decidiu pelo bloqueio da ordem executiva por entendê-la inconstitucional.

Em Los Angeles, o prefeito Eric Garcetti proibiu por decreto os funcionários municipais de colaborar com o governo federal nessa temática. No documento, o prefeito destacou que "a cidade não ajudará ou cooperará com qualquer esforço dos agentes federais de imigração para usar instalações ou recursos públicos para fins de aplicação da lei federal de imigração civil" (tradução nossa). ${ }^{24}$ No Judiciário, a Corte Federal de Los Angeles emitiu a decisão 170078 AB, que suspendeu a execução da proibição temporária do presidente Trump para a entrada de imigrantes de sete países de maioria muçulmana com liberação inicial para residência nosEstados Unidos.

Cabe destacar a aprovação da SB 54/2017 (California, 2017), que torna a Califórnia o primeiro "estado-santuário" do país. A lei, apresentada pelo presidente do Senado do estado, Kevin de León, beneficia imigrantes indocumentados de ações de deportação conduzidas pelo governo federal, restringe a colaboração com agentes de imigração da ICE e também objetiva fornecer assistência a estudantes e combater abusos e ameaças de deportaçóes feitas aos imigrantes indocumentados.

24. Disponível em: <https://www.lamayor.org/sites/g/files/wph446/f/page/file/Exec. \%20Dir.\%20No.\%2020--Standing\%20 with\%20lmmigrants.pdf>. 
O então Departamento de Justiça, na época administrado por Jeff Sessions, entrou com uma ação contra a SB 54/2017 e outras duas leis do estado da Califórnia voltadas à proteção de imigrantes indocumentados (United States of America, 2018). ${ }^{25}$ Segundo ele, as medidas da Califórnia obstruíam o trabalho dos oficiais federais e colocavam em risco as atividades destes ao abrir as fronteiras para radicais extremistas (Bruck, 2018). O governador à época, Jerry Brown, reagiu com irritação ao caso.

"Olha, sabemos que o governo Trump está cheio de mentirosos", disse Brown a repórteres. "Eles já se declararam culpados pelo conselho especial." Brown estava claramente agitado; seu rosto estava vermelho e ele gesticulou com o braço esquerdo para enfatizar sua angústia. "Eu diria - isso é pura especulação - que Jeff acha que Donald ficará mais feliz com ele, e tenho certeza de que Donald estará tuitando sua alegria por essa apresentação em particular", disse Brown. "Mas não se trata de aplicação da lei, náo se trata de justiça, e realmente deprecia o alto cargo para o qual ele foi nomeado" (Bruck, 2018, tradução nossa).

O processo está em andamento, mas, em julho de 2018, o juiz da Corte Federal John Mendez tomou uma decisão preliminar limitando a aplicação de três provisôes da lei. Em sua decisão, ele discutiu sobre a difícil posição da Corte em balancear o poder do governo federal na determinação de leis imigratórias contra os poderes estaduais. Apesar disso, decidiu pela suspensão de três aspectos da $A B$ 450, por entender que a lei infringia a soberania dos Estados Unidos. Os dispositivos específicos que foram suspensos estão vinculados à situação de empregadores que voluntariamente consentem em permitir a atuação de agentes de imigração em suas empresas (United States of America, 2018).

Outra fonte de desgaste da Califórnia com o governo central tem sido o ativismo do estado na criaçáo de uma agenda voltada à implementaçáo das políticas de mudanças climáticas. Apesar de ser um ator subnacional, o estado busca desempenhar papéis nessa área política semelhantes aos dos Estados-nação, procurando assumir um papel de liderança. Como destacam Mazmanian, Jurewitz e Nelson (2008, p. 401, tradução nossa),

os líderes políticos da Califórnia e os principais pesquisadores de políticas de mudança climática do país argumentam que a Califórnia está liderando os Estados Unidos na promulgação de políticas para reduzir as emissões de gases de efeito estufa (...). Essas políticas visam reduzir substancialmente a quantidade de combustíveis fósseis usados no estado e, assim, a intensidade de carbono do uso de energia do estado. Também se destinam a inspirar e incentivar açóes coordenadas de outros estados ocidentais e províncias canadenses adjacentes e a alinhar o estado com as principais políticas adotadas na União Europeia.

25. 0 Departamento de Justiça questionou as leis AB 450, SB 54 e AB 103 ao argumentar que tais medidas obstruíam o trabalho e a aplicação das leis de imigração federais (United States of America, 2018). 
O estado também participa de alianças estaduais voltadas para a mitigação e a adaptação às mudanças climáticas, tais como: i) West Coast Governors' Global Warming Initiative, criada em 2003; ii) Western Governors' Association on Energy Issues, em 2006; iii) Western Climate Initiative, em 2007; e iv) U.S. Climate Alliance, em junho de 2017, logo após o anúncio de Donald Trump da retirada dos Estados Unidos do Acordo de Paris.

O então governador da Califórnia, Jerry Brown, acompanhado de Jay Inslee, governador de Washington, e de Andrew Cuomo, de Nova Iorque, anunciou a construção de uma aliança de estados comprometidos com o cumprimento do Acordo de Paris (Tabuchi e Fountain, 2017). Tal compromisso resultou na formação da U.S. Climate Alliance, que conta com a participação de dezesseis estados norte-americanos e de Porto Rico, e tem por objetivo estabelecer a liderança dos estados na promoção de políticas de mudanças climáticas (USCA, 2018). Em 2018, o estado organizou e sediou o Global Climate Action Summit, com o objetivo de mobilizar atores não estatais comprometidos com a mitigação das mudanças climáticas para um encontro de experiências e avanços em políticas.

Embora a Califórnia tenha uma atuação histórica nessa temática, é possível observar que, no governo Trump, o estado vem atuando nessa frente também como uma plataforma política de resistência à Casa Branca. Como destaca o The New York Times, "de todas as batalhas que está travando com Washington, nenhuma tem as implicaçôes globais daquela sobre as mudanças climáticas" (Davenport e Nagourney, 2017, tradução nossa).

A instrumentalização da atuação internacional para fins políticos é tema de destaque na literatura sobre a atuação de governos subnacionais. Hocking (2004) e Keating (1999) identificam motivações variadas, que envolvem questóes de ordem econômica, política e social. Schiavon (2010) destaca que o ativismo internacional de estados pode ser usado como mecanismo de diferenciação do Executivo local diante do próprio Executivo nacional, "particularmente quando eles vêm de diferentes partidos políticos ou defendem ideologias opostas” (Schiavon, 2010, p. 11, tradução nossa). Esse parece ser o tipo de ativismo adotado pelo estado da Califórnia atualmente, sobretudo quando consideramos que os democratas náo possuem maioria no Congresso e vêm buscando ocupar espaços de poder no cenário doméstico.

Situação semelhante é observada quando analisamos os estados que reafirmaram seu compromisso com o Acordo de Paris. Dos dezesseis estados-membros da U.S. Climate Alliance, treze são liderados por membros do Partido Democrata. ${ }^{26} \mathrm{~A}$ atuação

26. Os estados de Califórnia, Colorado, Connecticut, Delaware, Hawaii, Minnesota, Nova Jersey, Nova Iorque, Carolina do Norte, Óregon, Rhode Island, Virgínia e Washington eram governados por integrantes do Partido Democrata, quando da inserção na U.S. Climate Alliance em 2017. Apenas Massachussets, Vermont e Maryland eram governados por integrantes do Partido Republicano. Essa análise foi desenvolvida a partir de dados fornecidos pela National Governors Association e pela U.S. Climate Alliance. 
da Califórnia nessa temática vem sendo criticada fortemente pelo governo federal. Em 2018, tal estado e outros dezessete processaram a administração Trump por flexibilizar e reconsiderar as leis estabelecidas pela administração Obama que regulavam a liberação de gases de efeito estufa de veículos produzidos no país. ${ }^{27} \mathrm{O}$ então chefe da Agência de Proteção Ambiental, Scott Pruitt, criticou as medidas da Califórnia ao argumentar que a ação do estado extrapola sua autonomia, prejudicando o federalismo norte-americano. Em reuniāo com a imprensa, o representante da agência nacional destacou que "o federalismo cooperativo não significa que um estado possa ditar padróes para o resto do país” (Mehrotra e Dlouhy, 2018, tradução nossa).

Outro desgaste mais recente no relacionamento entre a Califórnia e o governo Trump ocorreu em novembro de 2018, quando o presidente culpou a administração estadual pelos incêndios que afetaram a regiáo, causando a morte de 76 pessoas e um prejuízo para o estado de bilhóes de dólares (Holpuch e Anguiano, 2018), chegando inclusive a ameaçar retirar fundos federais ao estado (Osborne, Mallin e Zaru, 2018). O presidente voltou atrás após a repercussão negativa e as críticas de que ele estaria politizando uma tragédia.

\section{CONSIDERAÇÕES FINAIS}

O estudo sobre o relacionamento entre estados e governo federal nos Estados Unidos permite uma identificação complexa da formação do federalismo norte-americano, marcado por situaçóes envolvendo a cooperação entre os atores subnacionais, mas também tensóes e conflitos entre eles. Essa é uma característica do próprio desenho institucional do país e reflete, como vimos, as contradiçóes entre os interesses regionais. A defesa por maior autonomia estadual, característica dos debates entre os federalistas e os antifederalistas no século XVIII, permanece na política contemporânea e é motivo de embates no Judiciário, que passa a analisar a constitucionalidade das legislaçóes estaduais que tensionam com os interesses do governo central.

A aproximação com o federalismo dual no relacionamento entre esses atores é recorrente quando analisamos a condução da política exterior norte-americana, sendo uma característica a implementação de leis estaduais que entram em choque com os interesses do governo e que passam uma mensagem dúbia no plano das relaçóes internacionais. Esse tipo de ativismo estadual tem gerado preocupação, sobretudo porque, como destaca Fry (1998, p. 43, tradução nossa), "sem dúvida, complicou os esforços de Washington para falar a uma só voz sobre importantes questóes econômicas internacionais".

27. Disponivel em: <encurtador.com.br/blwTX>. 
Argumentamos neste trabalho que a atuação do estado da Califórnia, especialmente nos últimos anos, tem evidenciado essa face conflituosa do engajamento internacional dos governos estaduais norte-americanos. O estado vem liderando um forte movimento de reação às políticas imigratórias implementadas por Trump, gerando conflitos legais que questionam as limitaçóes estaduais para a regulamentação nessa temática. Além disso, o estado da Califórnia tem buscado exercer um papel de destaque na implementação de políticas para as mudanças climáticas, claramente contrárias à conduta assumida pelo atual presidente.

A agenda estadual tem evidenciado também a instrumentalização política do estado como mecanismo de resistência ao governo republicano, corroborando a hipótese desenhada por Schiavon (2010) de que o ativismo estadual tende a ser mais intenso quando o partido do governo estadual rivaliza com o partido do representante do Executivo nacional. Vale destacar que o próprio procurador do estado da Califórnia, Xavier Becerra, chegou a afirmar que a Califórnia seria o Texas de Trump, em referência às açóes jurídicas do estado do Texas que impediam a governabilidade do então presidente democrata (Sandoval, 2018).

A série de tensionamentos entre o governo da Califórnia e Washington permanece, e existe a possibilidade de que os conflitos sejam discutidos não apenas no âmbito doméstico, com a interferência da Suprema Corte, mas também no nível multilateral, a exemplo do que aconteceu com as sanções econômicas implementadas pelo estado de Massachusetts contra Burma (Denning e McCall, 2000) e que foram discutidas no âmbito da Suprema Corte e também da OMC. O caso foi emblemático ao trazer à tona as consequências do ativismo estadual nos Estados Unidos.

Os esforços da Califórnia para liderar coalizóes estaduais voltadas à implementação do Acordo de Paris e a participação do estado em reuniôes que debatem sobre o acordo também podem gerar um tensionamento a ser discutido para além da Suprema Corte, colocando em xeque a percepção de que a condução da política externa nos Estados Unidos é unificada.

\section{REFERÊNCIAS}

ALVAREZ, P. 16 states file lawsuit to stop Trump's national emergency declaration. CNN, 19 Feb. 2019. Disponível em: <https:/edition.cnn.com/2019/02/18/politics/ xavier-becerra-lawsuit-national-emergency/index.html>. Acesso em: 10 jan. 2019.

ANDERSON, G. Federalismo: uma introdução. Rio de Janeiro: FGV; São Paulo: Idesp, 2009.

BERNSTEIN, S. More californians dreaming of a country without Trump: poll. Reuters, 23 Jan. 2017. Disponível em: <https://www.reuters.com/article/us-usatrump-california-secession-idUSKBN1572KB>. 
BRUCK, C. Inside California's war on Trump. The New Yorker, 19 Mar. 2018. Disponível em: <https://bit.ly/2DzwuJa>.

CALIFORNIA. Senate Bill no. 1037. Energy efficiency. California Legislative Information, 29 Sept. 2005. Disponível em: <http://leginfo.legislature.ca.gov/ faces/billNavClient.xhtml?bill_id=200520060SB1037>.

. Assembly Bill no. 2021. Public utilities: energy efficiency. California Legislative Information, 29 Sept. 2006. Disponível em: <http://leginfo. legislature.ca.gov/faces/billNavClient.xhtml?bill_id=200520060AB2021>.

. Senate Bill no. 54. Law enforcement: sharing data. California Legislative Information, 10 May 2017. Disponível em: <https://leginfo.legislature.ca.gov/ faces/billTextClient.xhtml?bill_id=201720180SB54>.

CORNELL, S. The other founders: anti-federalism and the dissenting tradition in America, 1788-1828. Virginia: University of North Carolina Press, 1999.

CORWIN, E. S. The passing of dual federalism. Virginia Law Review, v. 36, n. 1, p.1-24, Feb. 1950.

DAVENPORT, C.; NAGOURNEY, A. California engages world and fights Washington on climate change. The New York Times, 23 May 2017. Disponível em: <https://www.nytimes.com/2017/05/23/us/california-engages-world-and-fightswashington-on-climate-change.html>.

DELGADO, E. Trump administration still separating families at border, advocates say. The Guardian, 12 Feb. 2019. Disponível em: <https://www.theguardian.com/ us-news/2019/feb/12/trump-el-paso-family-separations-migrants-immigration>.

DENNING, B.; MCCALL, J. States' rights and foreign policy: some things should be left to Washington. Foreign Affairs, v. 79, n. 1, p. 9-14, Jan./Feb. 2000.

EDWARDS, D. V.; LIPPUCCI, A. Practicing American politics: an introduction to government. New York: Worth Publishers, 1998.

ELAZAR, D. J. Exploring federalism. Alabama: The University of Alabama Press, 1987.

FOX, F. W. The American founding. London: Pearson, 2003.

FRANK, P. E. Global governors: foreign affairs activities among the 50 American states. 1998. Dissertação (Mestrado) - California State University; Northeastern University, California, 1998.

FRY, E. H. The expanding role of state and local government in U.S. foreign affairs. New York: Council on Foreign Relation Press, 1998.

GRODZINS, M. The American system. Chicago: Rand McNally, 1966. 
HOBSBAWM, E. Democratizaçáo, democracia e terrorismo. Sáo Paulo: Companhia das Letras, 2007.

HOCKING, M. Uma perspectiva das relaçóes internacionais. In: VIGEVANI, T. et al. (Org.). A dimensáo subnacional e as relaçóes internacionais. São Paulo: Unesp, 2004.

HOLPUCH, A.; ANGUIANO, D. Trump blames forest management again on California fires visit. The Guardian, 18 Nov. 2018. Disponível em: $<$ https:/www.theguardian.com/us-news/2018/nov/17/donald-trump-visitcalifornia-wildfires $>$.

IVANOVA, I. California to go 100 percent carbon-neutral. CBS News, 10 Sept. 2018. Disponível em: <https://www.cbsnews.com/news/california-aims-to-go100-percent-carbon-neutral/>.

KEATING, M. Regions and international affairs: motives, opportunities and strategies. In: ALDECOA, F; KEATING, M. Paradiplomacy in action: the foreign relations of subnational governments. London: Frank Cass, 1999.

KINCAID, J. From cooperative to coercive federalism. The Annals of the American Academy of Political and Social Science, v. 509, n. 1, p. 139-152, 1990.

KLINE, J. State government influence in U.S. Lexington: Lexington Books, 1983.

MANCHESTER, J. California secession movement cleared to begin collecting signatures. The Hill, 24 June 2018. Disponível em: <https://thehill.com/ homenews/state-watch/384662-california-secession-movement-gets-cleared-tobegin-collecting $>$.

MAZMANIAN, D. A.; JUREWITZ, J.; NELSON, H. California's climate change policy: the case of a subnational state actor tackling a global challenge. The Journal of Environment and Development, v. 17, n .4, p. 401-423, 2008.

MEHROTRA, K.; DLOUHY, J. A. California challenges Trump EPA over auto-emissions rollback. Bloomberg, 1 May 2018. Disponível em: <https:// www.bloomberg.com/news/articles/2018-05-01/california-challenges-trump-sepa-over-auto-emissions-rollback>.

MIROFF, N. DHS extends protections for immigrants with temporary status complying with courts. The Washington Post, 28 Feb. 2019. Disponível em: <https://www.washingtonpost.com/national/dhs-extendsprotections-for-immigrants-with-temporary-status-complying-withcourts/2019/02/28/06161f64-3b8a-11e9-a06c-3ec8ed509d15_story. html?utm_term $=$. b1fd30091221>. 
MORGAN, I. W.; DAVIES, P. (Ed.). The federal nation: perspectives on American federalism. New York: Palgrave Macmillan, 2008.

OSBORNE, M.; MALLIN, A.; ZARU, D. Trump threatens to pull federal funding for California wildfires over 'gross mismanagement'. ABC News, 11 Nov. 2018. Disponível em: <https://abcnews.go.com/US/trump-threatenspull-federal-funding-california-wildfires-gross/story?id=59102371>.

PRADO, D. F. M. Federalismo e política internacional: os conflitos entre a Uniāo e os governos estaduais nos Estados Unidos. 2013. Tese (Doutorado) Universidade Estadual de Campinas, Campinas, 2013.

PURDUM, T. S. California is at war with the Trump White House. The Atlantic, 6 Mar. 2019. Disponível em: <https://www.theatlantic.com/politics/ archive/2019/03/california-governor-gavin-newsom-warring-trump/584029/>.

RABE, B. G. States on steroids: the intergovernmental odyssey of American climate policy. Review of Policy Research, v. 25, n. 2, p.105-128, 2008.

RAPHAEL, R. Founding myths: stories that hide our patriotic past. New York: The New Press, 2014.

REIS, S. Saída do Acordo de Paris reduz liderança dos Estados Unidos. Observatório Político dos Estados Unidos, 27 jun. 2017. Disponível em: <http://www.opeu.org.br/2017/06/27/saida-acordo-de-paris-reduz-liderancados-eua/>. Acesso em: 14 abr. 2018.

RIOTTA, C. U.S. Military to send more than 5.000 troops to border ahead of migrant caravan arrival. Independent, 29 Oct. 2018. Disponível em: <https:// www.independent.co.uk/news/world/americas/us-politics/migrant-caravan-armyborder-troops-us-military-mexico-refugees-trump-threat-a8607001.html>.

SAGER, M. A. Cooperation without borders: federalism and international trade. Virginia: George Mason University Press, 1998.

SALVADOR, B.; BATISTA, H. G. Separatistas ganham força nos EUA de Trump. O Globo, 12 mar. 2017. Disponível em: <https:/oglobo.globo.com/ mundo/separatistas-ganham-forca-nos-eua-de-trump-21043902>.

SANDOVAL, P. X. Califórnia, epicentro da resistência contra Trump. El País, 16 jan. 2018. Disponível em: <https://brasil.elpais.com/brasil/2018/01/14/ internacional/1515956980_382543.html>.

SCHIAVON, J. La diplomacia local de los gobiernos estatales en Mexico (2000-2010). Centro de Investigación y Docencia Económicas, n. 201, 2010. 
STORING, H. J.; DRY, M. (Ed.). The anti-federalist: writings by the opponents of the constitution. Chicago: Abridged, 1985.

TABUCHI, H.; FOUNTAIN, H. Bucking Trump, these cities, states and companies commit to Paris Accord. The New York Times, 1 June 2017. Disponível em: <https:/www.nytimes.com/2017/06/01/climate/americancities-climate-standards.html? register=email\&auth=register-email\&_r $=0>$.

TEIXEIRA, T. Proibição à imigração de muçulmanos entra em vigor. Observatório Político dos Estados Unidos, 13 jan. 2017. Disponível em: $<$ https://www.opeu.org.br/2017/07/13/proibicao-imigracao-de-muculmanospassa-vigorar-com-ressalvas/>.

. Às vésperas das eleições, Trump endurece contra imigração. Observatório Político dos Estados Unidos, 11 ago. 2018. Disponível em: <https://www.opeu. org.br/2018/11/08/trump-endurece-contra-imigracao/>.

UN - UNITED NATIONS. Paris Agreement. New York: UN, 2015. Disponível em: <https://bit.ly/2oOJKXB>.

UNITED STATES OF AMERICA. Executive order: border security and immigration enforcement improvements. The White House, 25 Jan. 2017a.

. Executive order: enhancing public safety in the interior of the United States. The White House, 25 Jan. 2017 b.

. Justice Department files preemption lawsuit against the state of California to stop interference with federal immigration authorities. The U.S. Department of Justice, 7 Mar. 2018. Disponível em: <https://www.justice.gov/opa/pr/justicedepartment-files-preemption-lawsuit-against-state-california-stop-interference>.

USCA - UNITED STATES CLIMATE ALLIANCE. Fighting for our future: growing our economies and protecting our communities through climate leadership. [s.l.]: USCA, 2018. p. 1-39. Disponível em: <https://bit.ly/2YDHJ1Q>.

VARINSKY, D.; MOSHER, D.; SCHWARTZ, A. 5 claims Trump used to justify pulling the U.S. out of the Paris Agreement - and the reality. Business Insider, 1 June 2017. Disponível em: <http://www.businessinsider.com/fact-checktrump-reasons-for-leaving-paris-agreement-2017-6/\#job-losses-1>.

WALKER, D. American federalism: past, present and future. Journal of State Government, v. 62, n. 1, p. 3-11, 1989.

WILLS, G. Inventing America: Jefferson's declaration of independence. London: Vintage, 2018.

WRIGHT, D. S. Understanding intergovernmental relations. California: Brooks/Cole Pub, 1988. 
ZIMMERMAN, J. F. Interstate relations: the neglected dimension of federalism. London: Praeger Publishers, 1996.

ZINN, H. A people's history of the United States: 1492 to present. New York: Harper Collins, 2010.

\section{BIBLIOGRAFIA COMPLEMENTAR}

AMAR, V. D.; SCHAPS, M. How strong is San Francisco's 'sanctuary city' lawsuit against the Trump administration? Verdict, 10 Feb. 2017. Disponível em: <https:// verdict.justia.com/2017/02/10/strong-san-franciscos-sanctuary-city-lawsuittrump-administration>.

CAMERON, D. How sanctuary cities work, and how Trump's blocked executive order could have affected them. The Washington Post, 18 Jan. 2017. Disponível em: <https://www.washingtonpost.com/graphics/national/sanctuarycities/\#comments>.

HARVEY, C. In a fiery speech California governor Jerry Brown defends climate action and attacks 'alternative facts'. The Washington Post, 24 Jan. 2017. Disponível em: <https://www.washingtonpost.com/news/energy-environment/wp/2017/01/24/ in-a-fiery-speech-california-gov-jerry-brown-defends-climate-action-and-attacksalternative-facts/?utm_term=.650d5f86cfa8 $>$. Acesso em: 7 mar. 2018.

ICE - U.S. IMMIGRATION AND CUSTOMS ENFORCEMENT. ICE Report, Feb. 2017. Disponível em: <https:/www.ice.gov/doclib/ddor/ ddor2017_02-11 to02-17.pdf.>. Acesso em: 10 abr. 2018.

LEE, J. C.; OMRI, R.; PRESTON, J. What are sanctuary cities? The New York Times, 6 Feb. 2017. Disponível em: <https:/www.nytimes.com/interactive/2016/09/02/us/ sanctuary-cities.html>.

LEVIN, S. Resisting the resistance: anti-liberal rage brews in California's right wing. The Guardian, 7 Feb. 2018. Disponível em: <https://www.theguardian.com/usnews/2018/feb/07/new-california-movement-rightwing-resistance-liberal-trump>.

LOPES, I. F. F. A atuaçáo internacional dos estados norte-americanos para a implementaçáo das políticas de mudanças climáticas: o caso da Califórnia. 2019. 125 f. Dissertação (Mestrado) - Universidade Federal de Uberlândia, Uberlândia, 2019.

NYERS, P. Liberating irregularity: no borders, temporality, citizenship. In: GUILLAUME, X.; HUYSMANS, J. (Ed.). Citizenship and security: the constitution of political being. New York: Routledge, 2013. 
STORING, H. J. (Ed.). The complete anti-federalist: objections of non-signers of the constitution and major series of essays at the outset. Chicago: University of Chicago Press, 1981. v. 2.

THOMPSON, S. A.; BAJAJ, V. Green energy revolution will happen without Trump. The New York Times, 20 June 2017. Disponível em: <https://www.nytimes. com/interactive/2017/06/20/opinion/green-energy-revolution-trump.html?action= click\&pgtype=Homepage $\&$ clickSource=story-heading $\&$ module $=$ opinion $-\mathrm{c}-$ col-left region\&region=opinion-c-col-left-region\&WT.nav=opinion-c-col-left-region>.

'THOUSANDS' more migrant children may have been separated at border. BBC, 17 Jan. 2019. Disponível em: <https://www.bbc.com/news/world-uscanada-46912915>.

WILSON, S. In California a direct - if expensive - resistance to Trump's Washington. The Washington Post, 16 Oct. 2017. Disponível em: <https://www. washingtonpost.com/national/2017/10/16/in-california-a-direct-if-expensiveresistance-to-president-trumps-washington/?utm_term=.1068e86a7809>. Acesso em: 7 mar. 2018.

ZEZIMA, K. While the country shifts to the right, California continues to move left. The Washington Post, 11 Nov. 2016. Disponível em: <https://www. washingtonpost.com/politics/while-the-country-shifts-to-the-right-californiacontinues-to-move-left/2016/11/10/1c6cc602-a6d9-11e6-ba59-a7d93165c6d4_ story.html?utm_term=.9d50c2348731>. Acesso em: 12 abr. 2018.

California is a nation not a state: a fringe movement wants a break from the U.S. The Washington Post, 18 Feb. 2017. Disponível em: <https:// www.washingtonpost.com/politics/california-is-a-nation-not-a-state-a-fringemovement-wants-a-break-from-the-us/2017/02/18/ed85671c-f567-11e6-8d72263470bf0401_story.html?utm_term=.5c37ccf5283e.>. Acesso em: 12 abr. 2018. 